\title{
Colombia y México: hacia ¿diplomacias democráticas de baja intensidad?*
}

MARTHA ARDILA**

\begin{abstract}
Artículo recibido: 14 de diciembre de 2014
\end{abstract}
Artículo aprobado: 17 de marzo de 2015

Doi: dx.doi.org/10.12804/desafios27.2.2015.07

Para citar este artículo: Ardila, M. (2015). Colombia y México: hacia ¿diplomacias democráticas de baja intensidad? Desafíos, 27(II), 221-252. Doi: dx.doi.org/10.12804/desafios27.2.2015.07

\section{Resumen}

Colombia y México presentan diferencias y similitudes en la inserción internacional de los últimos diez años. Tienen en común la estrecha relación con los Estados Unidos, los problemas de seguridad y la profundización de una diplomacia económica. Estos dos paises han sido vistos como democracias estables. No obstante, situaciones vinculadas con las características del Estado y la estrechez del régimen politico hacen que se asemejen a diplomacias democráticas de baja intensidad. México, a diferencia de Colombia, tiende a vincular actores no gubernamentales en el proceso decisorio. Palabras clave: México, Colombia, política exterior, democracia, actores no gubernamentales, potencia regional, diplomacia paralela.

\footnotetext{
* Una versión preliminar de este artículo fue presentada en el Tercer Congreso de la Red Colombiana de Relaciones Internacionales (Redintercol), realizado en la Universidad Eafit de Medellín, el 27 y 28 de febrero de 2014.

** Politóloga internacionalista, $\mathrm{PhD}$. Docente investigadora y directora del Centro Latinoamericano y del Caribe del Centro de Investigaciones y Proyectos Especiales (CIPE) de la Facultad de Finanzas, Gobierno y Relaciones Internacionales de la Universidad Externado de Colombia. Correo electrónico: martha.ardila@uexternado.edu.co
} 


\title{
Colombia and Mexico: Heading Towards Low- Intensity Diplomatic Democracies?
}

\begin{abstract}
Colombia and Mexico have had differences and similarities in their foreign policy over the past ten years. They share a close relationship with the United States, common security issues and the elaboration of an economic diplomacy. The two countries have been considered stable democracies. Circumstances related to the states' characteristics and the narrowness of the political regime make them similar in terms of the low intensity of democratic diplomacy. However, Mexico, unlike Colombia, tends to involve non-governmental actors in the decision-making process.
\end{abstract}

Keywords: Mexico, Colombia, foreign policy, democracy, non-governamental actors, regional power, second-track diplomacy.

\section{A Colômbia e o México: para diplomacias democráticas de baixa intensidade?}

\begin{abstract}
Resumo
A Colômbia e o México apresentam diferenças e similitudes na inserção internacional dos últimos dez anos. Têm em comum a estreita relação com os Estados Unidos, os problemas de segurança e o aprofundamento de uma diplomacia económica. Estes dois países têm sido vistos como democracias estáveis. No entanto, situações vinculadas com as características do Estado e a estreiteza do regime politico fazem que se assemelhem a diplomacias democráticas de baixa intensidade. O México, a diferença da Colômbia, tende a vincular atores não governamentais no processo decisório.
\end{abstract}

Palavras-chave: México, Colômbia, política exterior, democracia, atores não governamentais, potência regional, diplomacia paralela.

\section{Introducción}

En América Latina, se evidencian diferentes tipos de diplomacias. Las hay tradicionales que enfatizan exclusivamente en el Estado; otras más nuevas que incluyen actores no gubernamentales y que tienden a ser más democráticas. En esta dirección, se observa una doble tran- 
sición: la del autoritarismo a la democracia y la del agotamiento de la matriz estato-centrista (Cavarozzi y Casullo, 2001). La democracia se vincula con la política exterior y el proceso de toma de decisiones, y la diplomacia democrática y participativa empieza a tomar fuerza en la región, la cual muestra variaciones en América Latina, y diferencias entre Colombia y México.

Por otra parte, analistas internacionales han identificado grupos de países transformacionales, contestatarios o hegemónicos (Badie, 2004); o no alineados, líderes de bloques, balanceadores o satélites (Holsti, 1970); o procore o anticore, autónomos-dependientes y/o ideológicos (Hey, 1997); populistas con democracias delegativas y socialdemócratas (Pérez Llana, 2007); y/o pragmáticos e ideológicos (Gardini, 2011); y/o con una lógica de aquiescencia o de autonomía (Rusell \& Tokatlian, 2013).

Colombia y México, a pesar de inscribirse dentro de un modelo neoliberal y aperturista que comparten, hacen parte de diferentes grupos de países y diplomacias, aunque en términos generales son procore, dependientes y pragmáticos, y sus orientaciones se acentúan según los gobernantes de turno. Hay casos en los que se muestran más ideológicos.

Tradicionalmente, estos dos países han sido vistos como democracias estables si se compara con otros Estados latinoamericanos que fueron víctimas de dictaduras militares. No obstante, situaciones vinculadas con las propias características del Estado y con la estrechez del régimen político hacen que se asimilen a una democracia de baja intensidad que conduce al ejercicio de una diplomacia paralela. Por su parte, México, a diferencia de Colombia, a pesar de caracterizarse como un Estado autoritario - sobre todo con el Partido de la Revolución Institucional (PRI) - , tiende a vincular actores no gubernamentales en el proceso decisorio.

La hipótesis que busca demostrar este artículo es que Colombia y México presentan diferencias y similitudes en su política exterior, tendientes hacia una nueva diplomacia democrática de baja intensidad, 
en cuanto a su internacionalización, tratamiento de la seguridad e inclusión de actores no gubernamentales.

El documento tiene en cuenta elementos de la interdependencia compleja y del realismo neoclásico, que vincula aspectos internos y la percepción de actores diferentes al Estado. Para la demostración de la hipótesis, se emplearon herramientas metodológicas de análisis de política comparada basadas en las diferencias y las similitudes, los cambios y las continuidades. A la vez, se utilizaron fuentes primarias, como informes oficiales, discursos y prensa, y secundarias, como textos académicos.

Este artículo se encuentra dividido en tres partes. La primera de ellas examina la interrelación entre diferentes tipos de países, su política exterior y la democracia, mostrando la complejidad de pertenencia e inserción de México y Colombia como potencias regionales de diferente rango. La segunda parte analiza las diferencias y similitudes de la política exterior colombiana y mexicana durante los últimos diez años en cuanto a su internacionalización y seguridad. Aspectos vinculados con lo geoestratégico y la diplomacia económica adquieren un especial significado. La tercera parte profundiza la participación de los actores no estatales en la toma de decisiones de los dos países. En este sentido, se analizan los gobiernos mexicanos de Vicente Fox, Felipe Calderón y comienzos de Enrique Peña Nieto, y los de los colombianos Álvaro Uribe y Juan Manuel Santos.

México y Colombia conformaron el Grupo de los Tres, y actualmente tienen un tratado de libre comercio (TLC); también fomentaron acciones conjuntas hacia el Gran Caribe, como cuando se creó la Asociación de Estados del Caribe, y hacen parte del Proyecto Mesoamérica y de la Celac. ¿Cómo se ubican Colombia y México en la jerarquía de poder regional? ¿Qué diferencias y similitudes actuales presentan en su política internacional? Para responder a estas preguntas, se analizan variables como la internacionalización, seguridad y diplomacia no gubernamental. 


\section{Tipos de países y democracia's' en América Latina}

América Latina es heterogénea y dentro de ella podemos ubicar diferentes grupos de países que van desde el Cono Sur hasta Centroamérica y México, además del Caribe Insular, con distintas vulnerabilidades, desarrollos y dependencias, con nuevas alianzas y nuevos 'polos'.

Por otra parte, en la región predomina la democracia como la mejor forma de gobierno, aunque se observan problemas de gobernabilidad e institucionalidad. Los índices de desarrollo democrático que se vienen midiendo desde 2002 muestran a México con un desarrollo medio, mientras a Colombia con un desarrollo bajo. Costa Rica, Chile y Uruguay son los países que presentan un mayor desarrollo de la democracia, mientras que Venezuela indica un desarrollo democrático mínimo. Costa Rica, Chile, Uruguay y México son de los más altos, y Colombia se encuentra al nivel de El Salvador, Honduras y Paraguay (KAS, 2012).

A nivel general, podemos observar tres tipos de países que en su vinculación con la democracia presentan diversas interacciones. En primer lugar, la denominada Nueva Izquierda, que busca políticas más autónomas frente a los Estados Unidos (Pérez Llana, 2007), que construye nuevas alianzas entre los países que la integran y con otros polos de poder como China. Con variadas diferencias, aquí ubicamos a Venezuela, Bolivia, Ecuador, Argentina y Nicaragua. El liderazgo de Venezuela dentro de este grupo y en el ALBA resulta claro. No obstante, se observan diferencias entre una izquierda ideológica y otra pragmática, y dentro de esta última se encuentra Argentina. La primera presenta variaciones frente al modelo económico de desarrollo con énfasis social y concentración del poder, mientras la segunda, la pragmática, continúa con un modelo neoliberal. En ella, ha habido fuertes críticas al modelo de democracia que aplican, caracterizado por la prolongación del poder, la desinstitucionalización, y en algunos de ellos, como Venezuela, la militarización.

Varios cambios a nivel internacional inciden en la ubicación de estos países, en sus proyectos políticos y en sus nuevos lineamientos 
externos y regionales. Entre ellos, como se mencionó, está la ola rosa suramericana, la de Chávez, Morales y Correa, por una parte, y la de Brasil, Argentina y Uruguay, por la otra, las cuales presentan fuertes vínculos entre ambas, diferencias que mezclan diversos elementos: comparten un modelo híbrido que combina la democracia radical y la representativa, con jefes de Estado que fueron elegidos, por lo general, con amplia votación, que tienen un Congreso que los respalda, que hacen partícipes a diferentes actores en el proceso de toma de decisiones, que buscan diversificar sus relaciones internacionales, que han realizado reformas constitucionales, que utilizan símbolos patrios y que han continuado radicalizando sus propuestas iniciales (Ellner, 2012). Como diría O’Donnell, son democracias delegativas, pero también sistemas políticos autoritarios y cerrados.

Estos países plantean un modelo de desarrollo diferente con mayor participación del Estado, políticas sociales y grandes restricciones a la inversión extranjera. En el caso venezolano, el esquema se basa en la renta petrolera, aunque suele señalarse que el modelo anterior sufrió un agotamiento y se habla de un desarrollo y de una democracia endógena. Durante los primeros años de la Revolución Bolivariana del siglo XXI, Venezuela tuvo un crecimiento económico motivado por la renta petrolera, lo que condujo al mejoramiento de los principales indicadores sociales del país y a la disminución de la pobreza. En la actualidad, se observan problemas vinculados con la falta de garantías a la oposición, la libertad de expresión, la inseguridad y la crisis económica ocasionada por la disminución de los precios del petróleo a nivel internacional.

Hay un segundo grupo de países donde ubicamos a Brasil y México, que son las potencias regionales por excelencia. Brasil, cuya proyección se expande a toda Suramérica, aspira a ser un jugador global y es más pragmático. No obstante, el gran cuestionamiento gira en torno a si las ambiciones internacionales brasileñas requieren de su posicionamiento regional y de un liderazgo que incluye costos internos - como los económicos y el apoyo de la población-y externos, en términos de garantizar un mayor bienestar suramericano y de brindar herramientas para su desarrollo económico que conduzcan a un impacto 
regional y no solo de un país. En ese orden de ideas, colaborar y ser mediador, si así se le solicitara, en la solución de disputas interestatales - conflictos transfronterizos —, internas tanto políticas — diálogos con grupos alzados en armas, procesos orientados a la consolidación de la democracia - como económicas — infraestructura, mejor posicionamiento de los productos suramericanos-, entre otras. Todo ello implica un costo económico y político que probablemente Brasil por sí solo no esté dispuesto a asumir. Lo debe compartir entonces con otros países como Colombia y probablemente también con Chile y Perú. Ambos le interesan por su proyección hacia el Asia-Pacífico. Pero no lo compartiría con Venezuela, que en sus pretensiones de liderazgo cuenta con sus propios seguidores. Y tampoco lo haría con México, al que percibe como su más claro competidor y que geográficamente no hace parte de Suramérica.

Por su parte, México reúne una serie de características que lo definen como una potencia regional. ${ }^{1}$ Tiene una política exterior muy activa, ha sido mediador en conflictos este-oeste y norte-sur. Históricamente, se ha mostrado como un país 'pacifista' que poco se interesó por fortalecer su ejército. Durante los últimos años, ha venido aumentando su gasto militar, aunque todavía continúa siendo bajo: en 2012 fue del 0,6\% del PIB, mientras que en Colombia fue del 3,3\% (Banco Mundial, 2013).

Sin embargo, una potencia regional ${ }^{2}$ también se define con relación a una serie de variables cualitativas, como legitimidad, voluntad política y liderazgo. Y es que características cuantitativas y cualitativas

\footnotetext{
1 México reúne una serie de características que la definen como una potencia regional. Tiene una extensión de 1.138.914 kilómetros cuadrados; el 2,5\% del agua; una frontera con los Estados Unidos de más de 3 mil kilómetros, al sureste de 960 km con Guatemala y $176 \mathrm{~km}$ con Belice; una población de 98 millones de habitantes. Posee, a la vez, el $10^{\circ}$ PIB del mundo, es exportador, el tercer socio comercial de los Estados Unidos y tiene una gran biodiversidad. En 2010, el PIB de México tuvo un crecimiento del 5,3\%, debido al repunte de sus exportaciones y a su inflación del 4,4\% (Cepal, 2011). En 2012, el crecimiento del PIB fue del 3,8\%, pero, para 2013, su expansión se contrajo y redujo al $1,2 \%$, por el bajo gasto público, la caída en la construcción y la débil demanda estadounidense de las exportaciones mexicanas (FMI, 2014).

2 Al respecto puede consultarse Flemes (2012), Notle (2010), Desdradi (2009) y Rocha
} 
inciden en la calificación de las potencias regionales. En las primeras, se ubican aspectos relacionados con los recursos naturales, el gasto militar, la población, la extensión y el comercio; mientras que en las segundas, elementos vinculados con el poder suave, la legitimidad, el liderazgo, la voluntad política y la confianza, resultan fundamentales. Es decir, la percepción tanto de la población a nivel interno como la que tienen los demás países constituye elementos que respaldan estas categorizaciones.

Y México, a pesar de que ganó legitimidad con el 'bono democrático' que le brindó la transición hacia la democracia y el fin de la hegemonía del PRI, ha venido perdiendo credibilidad y confianza en los países de la región que lo perciben cada día más al lado de los intereses de los Estados Unidos. Ello le ha llevado a perder liderazgo en la región e, incluso, en su perímetro más cercano, como Centroamérica y Cuba. Hoy en día, los países latinoamericanos no confían en México para que represente sus intereses, y lo ven aliado a los Estados Unidos. Esto resulta claro con las encuestas de opinión desarrolladas por el CIDE (González, Schiavon, Crow, Maldonado, 2011) y por el Latinobarómetro.

Y, como si esto fuera poco, la presencia del narcotráfico, el crimen organizado, los escándalos de corrupción y los movimientos sociales a raíz de la desaparición de 43 estudiantes en Iguala, en julio de 2014, han debilitado al Estado mexicano, su imagen internacional y su proyección externa. México parece una potencia regional en descenso, mientras que Brasil, Venezuela, Chile, Argentina y Colombia se encuentran en ascenso. Hay estudios que indican la dificultad que presenta el país azteca para mantenerse como una potencia regional debido a su relación de cercanía con los Estados Unidos y de lejanía con América Latina (Bernal-Meza, 2009; Olga Pellicer, 2006; Guadalupe González, 2011), pero no solo esto, sino también sus problemas internos vinculados con la violencia hacen que México descienda en la jerarquía de poder regional.

(2011). Son análisis que examinan principalmente el poder regional bajo un enfoque teórico de realismo neoclásico. 
Finalmente, el tercer grupo de países partidarios de un regionalismo abierto, como Chile, Perú, Colombia y México. ${ }^{3}$ Los tres primeros son potencias regionales secundarias, pero de diferente magnitud. De todas maneras los países analizados hacen a su vez parte de diferentes grupos. Colombia, por ejemplo, es PRS y partidaria de un regionalismo abierto, y México es una PR primaria también partidaria del regionalismo abierto.

\section{Diferencias y similitudes en la inserción de México y Colombia. Internacionalización, seguridad y diplomacia económica}

Además de las tipologías mencionadas, los países con vertiente hacia el océano Pacífico son diferentes a los del Atlántico. Los primeros, donde se ubican Colombia y México, son partidarios del libre mercado y del regionalismo abierto, mientras que los segundos, como Venezuela, Argentina y Brasil, abogan por una mayor participación del Estado en la economía. Según proyecciones, los miembros de la Alianza del Pacífico crecerán más rápidamente, les llegará mayor inversión extranjera y tendrán menores niveles de inflación. ${ }^{4}$

En materia internacional, los primeros son más cercanos a los Estados Unidos, mientras los segundos buscan mayores niveles de autonomía y construyen nuevas alianzas políticas y económicas. No obstante, la política externa de Colombia y México tiene diferencias y similitudes, debido a la diversa historia, situación interna, vulnerabilidades y tendencias recientes. Veamos.

\footnotetext{
3 Colombia es un país mediano con una favorable ubicación geoestratégica, grandes recursos energéticos y ambientales, que busca atraer inversión extranjera y presenta un crecimiento del PIB per capita constante. Posee petróleo, gas y carbón, así como una gran riqueza en materia de biodiversidad. Se ubica como uno de los 19 países megadiversos del mundo, ocupando el tercer lugar en especies vivas, el segundo en aves y variedad de mariposas, y el primero en anfibios. Estas potencialidades podrían mejorar el poder negociador del país, su construcción de alianzas y su inserción internacional.

4 Según proyecciones de Morgan Stanley, los miembros de la Alianza del Pacífico (Chile, Colombia, México y Perú) crecerán un 4,25\% y los segundos tan solo un 2,6\%.
} 


\subsection{Geoestrategia e internacionalización}

Dos rasgos similares identifican a México y Colombia: su ubicación geográfica y su cercanía con los Estados Unidos, física en el caso de México con una frontera de más de 3.234 kilómetros, y más ideológica en el caso colombiano que mexicano. En el país azteca, se observa un gran debate en torno a su ubicación geográfica, polémica entre enfoques realistas e idealistas acerca de si deben o no fortalecer las relaciones con los Estados Unidos, el cual revierte en las posiciones del Partido Revolucionario Institucional (PRI), del Partido de la Revolución Democrática (PRD) y del Partido de Acción Nacional (PAN) desde el año 2000, cuando Vicente Fox llegó al poder. Después de dos sexenios, en 2012, el PRI ha regresado a la Casa de los Pinos con Enrique Peña Nieto.

La relación con los Estados Unidos, una ubicación geográfica con vertientes hacia el Pacífico y el Caribe, y los problemas de seguridad son aspectos que asemejan e inciden en las relaciones de México y Colombia con su mundo externo. Para ambos países, a lo largo de su historia, los Estados Unidos han sido el principal referente para su política exterior. En el caso de México, este país a mediados del siglo XIX perdió alrededor del $65 \%$ de su territorio, de Estados como Texas, Nuevo México y Arizona, que pasaron a manos de los Estados Unidos, territorios ricos en petróleo que dejaron una gran huella en el diseño y la ejecución de la política azteca. En Suramérica, también ha habido problemas fronterizos de Chile con Bolivia y Perú, de Ecuador con Perú y de Colombia con Venezuela.

Igualmente para Colombia, la separación de Panamá en 1903 afectó lo que serían sus vínculos internacionales. Pocos hechos han dejado una huella tan profunda para la inserción externa, convirtiendo a Colombia en un país 'introvertido, ${ }^{5}$ es decir que, a pesar de sus múltiples pertenencias, tiene una baja actividad y mira más hacia la

\footnotetext{
5 Ver publicaciones realizadas con ocasión del aniversario de los 100 años de la separación de Panamá de Colombia. Puede consultarse "El trauma de Panamá", editorial de ElTiempo, 2 de noviembre de 2003.
} 
parte continental que insular. Por su ubicación geográfica, Panamá significaba el punto de tránsito y encuentro de Colombia con el gran Caribe y su pérdida alteró nuestras relaciones internacionales, creando percepciones defensivas y débiles para el posicionamiento externo del país. Algo similar podríamos señalar acerca de los 75 mil kilómetros que Colombia perdió por el fallo de la Corte Internacional de Justicia de La Haya, frente a lo cual analistas internacionales muestran una creciente preocupación.

Las relaciones tanto de México como de Colombia con los Estados Unidos hacen parte de una interdependencia compleja asimétrica en la que el comercio y la inversión resultan relevantes. Los mexicanos siempre han tenido una relación más compleja que los colombianos con los Estados Unidos, la cual se profundiza e institucionaliza desde comienzos de la década de los noventa con la suscripción del Nafta en 1992 y su puesta en marcha dos años después. En 2013, las exportaciones aztecas a ese país fueron el $80 \%$ de las totales, que se ubican en el promedio de los últimos diez años y que en ocasiones han ascendido 2-3 puntos.

La ubicación geográfica constituye uno de los referentes para el diseño de la política exterior mexicana y tanto los analistas como los tomadores de decisiones le han otorgado un gran peso, especialmente por su frontera norte, debido a que fue víctima del expansionismo norteamericano mostrándose como un país débil frente a esa potencia. Para los colombianos, en cambio, la ubicación geoestratégica que tiene nuestro país con múltiples pertenencias hacia el Pacífico, el Caribe, la Amazonía y como región andina, además al estar situado en la parte norte de Suramérica, ha pasado desapercibida. El tener dos mares o casi tres con el Amazonas poco ha preocupado a los académicos y a los tomadores de decisiones. No hemos desarrollado una política marítima, como sí la tiene, por ejemplo, México, y qué decir de países como Chile y Perú. Colombia buscó más potenciar su relación con los Estados Unidos y la región andina que con otras áreas geográficas.

En México y Colombia, se observan cambios en su inserción externa, motivados principalmente por aspectos internos —económicos 
y políticos- e idiosincráticos. Con diferente magnitud, ambos países tienden a privilegiar una diplomacia económica, como veremos a continuación.

\subsection{La profundización de la diplomacia económica}

Desde la década de los ochenta, el gobierno azteca empezó a modificar su concepción de desarrollo económico y, para finales de esa década, México era una de las economías subdesarrolladas más abiertas, adoptando también medidas de liberalización para la inversión extranjera. Durante estos años y en especial con Carlos Salinas de Gortari, se inició y fomentó una diplomacia económica, marcada por el Nafta, la suscripción de tratados de libre comercio, el ingreso a diversas organizaciones, por ejemplo, el GATT en 1986, que aceleró reformas económicas que estaban en marcha, como la eliminación de requisitos para las licencias de importación. En esta década, México diseñó una arquitectura institucional también con la región Asia-Pacífico. Ingresó al APEC en 1993 y a la OECD un año después.

México cuenta con una red de 10 tratados de libre comercio con 45 países, 30 acuerdos para la promoción y protección recíproca de las inversiones, y 9 acuerdos de alcance limitado (acuerdos de complementación económica y acuerdos de alcance parcial) en el marco de la Aladi (Proméxico, 2014). ${ }^{6}$

Esta tendencia continúa desde 2013, con el priista Enrique Peña Nieto, y sus ideas modernizantes y reformadoras. Así lo demuestran las reformas energéticas y fiscales. La primera de ellas se abre a la empresa privada y a la inversión extranjera, lo cual desata grandes críticas en diversos sectores y en el mismo PRI, tal como lo demues-

\footnotetext{
6 Recuperado de http://www.promexico.gob.mx/comercio/mexico-y-sus-tratados-delibre-comercio-con-otros-paises.html (consulta realizada el 21 de febrero de 2015).

También puede consultarse: Secretaría de Economía de los Estados Unidos Mexicanos, 2015. Recuperado de http://www.economia.gob.mx/comunidad-negocios/comercio-exterior/ tlc-acuerdos (consulta realizada el 21 de febrero de 2015).
} 
tran medios de comunicación escritos como los periódicos Uno Más Uno y La Jornada, y las revistas Proceso y Nexos.

La agenda de su tercer año de gobierno incluye varios aspectos. El primer punto es la economía, vinculado con el crecimiento económico y el aumento del salario mínimo. El segundo, los planes de infraestructura y todo lo derivado de las reformas en energía y telecomunicaciones. El tercero, los temas de seguridad pública, relacionados con la percepción de la población y la construcción de instituciones. Finalmente y no por ello menos importante, la reforma educativa (Plan Nacional de Desarrollo, 2012).

Peña Nieto quiere aprovechar la herencia del activismo internacional que caracterizó el partido al que pertenece, y quiere continuar con el énfasis económico que ha impulsado el accionar externo mexicano. Por eso es que realizó una serie de visitas y se reunió con sectores empresariales no solo latinoamericanos, sino también de Asia y Europa, desde antes de su posesión.

Busca 'consolidar el papel constructivo de México en el mundo', por medio de una mayor presencia internacional, es decir, de una política más activa y de fortalecimiento de nuevas y viejas alianzas; de la difusión económica, turística y cultural del país; del compromiso con el libre comercio, la movilidad de capitales y la integración; y de la protección del migrante, tanto del mexicano en el exterior como de los extranjeros en ese país. En realidad, habrá que esperar para ver los cambios y diferencias que el gobierno de Peña Nieto ejecute frente a sus dos antecesores de coaliciones con el Partido de Acción Nacional. Aunque comenzó bien, su imagen se ha debilitado a raíz de la desaparición de los estudiantes en Iguala, y de casos de corrupción.

Por su parte y de manera más reciente, el gobierno colombiano también ha venido fomentando una diplomacia económica, la cual se profundiza con la llegada de Juan Manuel Santos, la búsqueda de atraer inversión extranjera y la suscripción de tratados de libre comercio. Ya son quince los TLC que nuestro país ha firmado. 
Colombia empezó a firmar acuerdos económicos un poco más tarde con Centroamérica (El Salvador, Guatemala, Honduras), Canadá, Estados Unidos. Tiene acuerdos de complementación económica con la CAN, Chile, Aladi y Caricom. En el marco de la CAN, Colombia, Ecuador, Venezuela con Mercosur, con Chile y con los países del Triángulo del Norte: El Salvador, Guatemala y Honduras. También los ha suscrito con Corea, Turquía, Suiza y la Unión Europea.

A su vez, desde 2010, los presidentes de Chile, México, Perú y Colombia vienen promoviendo una zona de integración profunda como estrategia de cooperación entre ellos y de inserción conjunta en el Asia-Pacífico, por medio de la Alianza del Pacífico. A pesar de los cambios de jefes de Estado en México y Chile, dicha tendencia continúa, como se vio con la reunión del Grupo de Alto Nivel a finales de enero del presente año. Hoy en día, la Secretaría Pro Tempore la tiene México.

\subsection{Diplomacia política y democrática}

En materia política, la interacción entre lo interno y lo externo también se vincula con la democracia, la cual se refleja en el ámbito internacional, al mismo tiempo que actores externos estatales y supranacionales ejercen, presionan y hacen una veeduría sobre situaciones de alteración democrática de los países. En este sentido, la comunidad internacional realiza un monitoreo sobre temas de la nueva agenda, como la protección y defensa de los derechos humanos. Organizaciones multilaterales, como la OEA y la ONU, la Unión Europea, y ONG, como Americas Watch, hacen un seguimiento y acompañamiento.

En Colombia, la Oficina del Alto Comisionado de las Naciones Unidas ha desempeñado un importante papel, razón por la cual resulta curioso e inexplicable que el gobierno central considere que el país no requiere de su colaboración debido a que la situación de los derechos humanos alcanzó el nivel deseado. Esta oficina fue creada en 1997 y su mandato cesaba el 31 de octubre de 2013. Organizaciones de la sociedad civil manifestaron su preocupación por la posible no renovación del mandato, dando lugar a la permanencia de esta oficina. 
Históricamente, por ser Colombia una democracia estable, la comunidad internacional percibió al Estado como protector de los derechos humanos. Fue tan solo a partir de 1989 en la Conferencia de las Naciones Unidas en Ginebra (Suiza) cuando empezó a preocupar la situación de los derechos humanos en el país. En lo sucesivo, se tendió a una política defensiva en materia de derechos humanos ${ }^{7}$ (Gallón, 2002).

Durante los años de la presidencia de Álvaro Uribe, se manejó una dualidad: por una parte, el manejo liderado por la Vicepresidencia y, por la otra, el discurso de Uribe que poco tenía que ver con las actividades que realizaba la Vicepresidencia de la República en este tema. Fueron los años de las denuncias por los falsos positivos.

La división del manejo de los derechos humanos continúa y se observan dos instancias: la de la Vicepresidencia y la de Cancillería, esta última más pasiva y reactiva. A partir del gobierno de Juan Manuel Santos (agosto de 2010), se inicia un diálogo con la sociedad civil representada por la Alianza de Organizaciones y la Mesa de Garantías, liderado por la Vicepresidencia y el Programa Presidencial de Derechos Humanos y Derecho Internacional Humanitario, orientado a diseñar para finales de 2013 una propuesta de lineamientos de política pública en derechos humanos. Con el segundo período de gobierno de Santos, el tema tiende a vincularse con la seguridad.

\footnotetext{
7 En este sentido, Gallón identifica varios tipos de diplomacia de derechos humanos: el anonimato apacible desde mediados de la década de los sesenta hasta mediados de la década de los ochenta; la cooperación vacilante durante el gobierno de Ernesto Samper, cuando se construye todo un andamiaje; y la diplomacia de la astucia desde mediados de los ochenta hasta comienzos de los noventa. En ellas predominaron tácticas como la de la astucia, la distracción y la vacilación (Gallón, 2002). Al finalizar el siglo Xx, se observa una sustitución de compromisos, diplomacia que se prolonga en el siglo XXI.

Durante los años en que estuvo Álvaro Uribe en la Presidencia de la República, se dio una reincorporación de grupos paramilitares a la vida civil, muchos de los cuales tuvieron nexos con el ejército. A la vez, se dieron serias acusaciones vinculadas con los llamados 'falsos positivos', que salen a la luz pública en 2008 y que se refieren al asesinato de civiles inocentes que el ejército realizaba a supuestos guerrilleros en combate para demostrar resultados en el contexto del programa de Seguridad Democrática. En 2010, el relator especial de las Naciones Unidas, luego de una visita a Colombia un año antes, denunció que existe "un patrón de ejecuciones extrajudiciales" y que la impunidad abarca el 98,5\% de los casos.
} 
No obstante, en otros aspectos también se observa un manejo contradictorio. La reforma del fuero militar, la actitud frente a la Comisión Interamericana de Derechos Humanos y la posibilidad del cierre de la Oficina del Alto Comisionado para Derechos Humanos muestran acciones en contravía del discurso oficial. Además, datos revelados por Somos Defensores indican que los asesinatos a defensores de derechos humanos van en ascenso.

Es así como en Colombia, a pesar de haber una democracia estable, se observan muchas fisuras, una baja calidad, falta de coordinación y acciones reactivas y discontinuas. Es por ello por lo que hablamos de una democracia de baja intensidad con problemas de institucionalidad y gobernabilidad, con varias agendas carentes de coordinación.

$\mathrm{Al}$ referirnos a la vinculación entre democracia y política exterior, tenemos que tener en cuenta instituciones como el Congreso, las Fuerzas Armadas y el Ministerio de Relaciones Exteriores. Y los colombianos, por ejemplo, durante los últimos diez años muestran mucha más confianza en sus Fuerzas Armadas que en el Congreso o en la Cancillería (Corporación Latinobarómetro, 2012).

En 2001, México llevó a cabo una reforma constitucional, orientada a la protección de los derechos humanos y al respeto de los tratados internacionales que suscribió en esta materia. A su vez, enfatizó en la protección de los defensores de derechos humanos y de los medios de comunicación (United Nations, 2013). Desde el gobierno de Vicente Fox, la embajada volante con Marie Claire Acosta y la Subdirección de Derechos Humanos en la Subsecretaría de Relaciones Exteriores se le viene prestando mayor atención a este tema. La posición de México frente a Cuba es congruente con esta tendencia. Algo similar sucede con los connacionales y la protección de sus derechos en el exterior. No obstante, la agudización de problemas de seguridad lleva de nuevo a alterar la situación y a aumentar las violaciones de derechos humanos en el país azteca. 


\subsection{Seguridad y relaciones internacionales}

Se observa un cambio en el manejo de la problemática de seguridad, adquiriendo gran relevancia en la relación de ambos países con los Estados Unidos. Frente a este tema, desde la década de los noventa, las drogas tienen un especial significado, hablándose de una 'narcotización’ de las relaciones de Colombia con los Estados Unidos.

A raíz de los atentados del 11 de septiembre de 2001, se vincula con los grupos armados y se habla de un 'narcoterrorismo' y de 'securitización’ de las relaciones internacionales. De manera más reciente, se agudiza el problema de las drogas, del crimen transnacional y de la inseguridad ciudadana en México. Durante la primera mitad del siglo XXI, este país ha transformado sus esquemas de seguridad tanto doctrinarios como institucionales y, desde 2001, se profundizan vulnerabilidades vinculadas con la seguridad fronteriza. En este sentido, se han suscrito convenios como el 'Acuerdo de Fronteras Inteligentes' (2002) y la Alianza para la Seguridad y la Prosperidad de América del Norte (Aspan, 2005). Para los Estados Unidos, la situación azteca resulta altamente preocupante por su frontera de 3.234 kilómetros, interdependiente y de fácil acceso.

Aquí resulta importante señalar que de manera reciente Colombia ha venido exportando su pericia en seguridad y hacia México, nuestro país ha venido cooperando en materia de seguridad. No solo la asesoría del general Óscar Naranjo, sino diferentes ámbitos policiales y militares prestan asesoría. ${ }^{8}$ No obstante, amplios sectores de la sociedad azteca rechazan la asesoría colombiana.

En términos generales, se observa una transición de una visión tradicional basada en la seguridad del Estado, las fronteras, la defensa, el territorio y la inteligencia, hacia otra mucho más amplia que abarca temas como seguridad ciudadana, democracia, derechos humanos y labores humanitarias. Se tiende a una visión multidimensional, y es

8 Entrevista al académico Raúl Benítez, UNAM, 16 de septiembre de 2014. 
un tema que también se debate en otras comisiones dando lugar a una concepción más transversal e interdisciplinaria.

El tratamiento de la seguridad y, con ello, de la situación interna, durante los últimos diez años en Colombia, resultó definitivo para la citación de los ministros y el control político. En general, la coyuntura interna define y moldea el tratamiento de los temas tratados en la Comisión Segunda del Congreso. Y durante esos años se dieron momentos de crisis diplomáticas con Ecuador y Venezuela, vinculados con violaciones al derecho internacional, como fue la Operación Fénix en 2008 y también en 2009-2010 respecto a la posibilidad de que los Estados Unidos utilizaran bases militares colombianas.

Los temas vinculados a la seguridad que se discutieron en el Congreso fueron:

En primer lugar, el de fronteras, especialmente con Venezuela y Ecuador. Dentro de este, fueron recurrentes aspectos relacionados con el medio ambiente y desastres naturales. A su vez, se debatió acerca de la crisis económica y su impacto en las zonas de frontera. En este sentido, además, se analizaron las tensiones fronterizas. Así mismo, se examinó la actualización de la Ley 191 de 1995 o Ley de Fronteras. No obstante, aún se encuentra pendiente su diseño por parte de los ministerios de Defensa y de Relaciones Exteriores. Resulta importante señalar que los congresistas procedentes de frontera se mostraron más activos en estos temas.

A la vez, se ha enfatizado en el caso venezolano y las amenazas externas que podría enfrentar la nación en temas militares, comerciales y políticos por parte del régimen venezolano gobernado por Hugo Chávez Frías y ahora por Nicolás Maduro, y el grado de preparación con que se cuenta para resolver este tipo de eventualidades. No olvidemos que la relación con este vecino se mueve entre largos períodos de tensión y desconfianza y cortos momentos de cordialidad. Al fin y al cabo existe una amenaza tradicional, como el diferendo entre los dos países por el Golfo de Venezuela o de Coquivacoa. 
En segundo lugar, la cooperación militar, principalmente por parte de los Estados Unidos, fue un tema que preocupó a la Comisión Segunda del Congreso colombiano, tal como consta en sus actas. El Acuerdo de Cooperación en Materia de Defensa firmado con ese país desató un amplio debate, que se extendió a la Unasur. No obstante, finalmente en septiembre de 2010 la utilización de bases militares por personal norteamericano fue derogada por la Corte Constitucional.

En tercer lugar, durante los últimos años, la seguridad ciudadana y, con ello, la seguridad urbana han sido un tema que acapara la atención de la Comisión Segunda del Congreso (Ardila, 2008). En este sentido, se ha discutido la búsqueda de cooperación internacional teniendo en cuenta la experiencia de otros países para combatir problemas de inseguridad, principalmente urbana, que viven algunas ciudades del país, como Medellín y Bogotá. De manera particular, resultan prioritarios aspectos relacionados con atracos y homicidios.

También se ha discutido acerca de la aspersión aérea, las fumigaciones y sus efectos en la frontera con Ecuador; los escenarios de crisis con Honduras; el proceso de paz y liberalización de los secuestrados; la información del computador de Raúl Reyes; la situación carcelaria, sobre todo en países fronterizos, como Ecuador; las labores de inteligencia Departamento Administrativo de Seguridad (DAS), como las 'chuzadas'; las intercepciones irregulares en las comunicaciones; la complicidad de las FF. AA. en actividades delictivas relacionadas con los falsos positivos y la limpieza social, los crímenes de Estado y falsos positivos, y la muerte en combate; el presupuesto asignado a las FF. AA.; la salud de las FF. AA.; e informes sobre derechos humanos.

Por su parte, en el Congreso mexicano, los principales temas discutidos durante los últimos diez años han sido: asuntos migratorios y de derechos humanos; Estados Unidos y Cuba, comercio, seguridad nacional, medio ambiente y terrorismo concentraron la agenda de política exterior del legislativo frente al ejecutivo (Velázquez, 2008).

A pesar de los puntos de acuerdo, se dan varios de confrontación en torno a las relaciones con los Estados Unidos y con Cuba, principal- 
mente por el voto mexicano en la Comisión de Derechos Humanos de la ONU y por el apoyo incondicional a los Estados Unidos luego del 11 de septiembre. Otro factor que agravó la relación fue el enfrentamiento abierto entre el primer secretario de relaciones exteriores del gabinete foxista, Jorge G. Castañeda, y los grupos parlamentarios (Velázquez, 2008).

Por su parte, Peña Nieto fija cinco objetivos vinculados con la pacificación del país, la equidad social, el mejoramiento de la educación, la transformación en una potencia económica emergente y la búsqueda de que México sea un actor con responsabilidad global (Villamar, 2013). Los dos últimos, que son los internacionales, han sido enfatizados en varias reuniones, y de alguna manera también apunta al respeto por el medio ambiente y por los derechos humanos. A su vez, reitera principios que lideró el PRI durante muchos años, como la soberanía, la autodeterminación y la no injerencia en los asuntos internos.

En Colombia, durante el gobierno del presidente Andrés Pastrana (1998-2002), se habló de una diplomacia por la paz, que se vincula con la internacionalización del conflicto interno colombiano. Comienza el Plan Colombia y Plan Patriota y una relación especial con los Estados Unidos que ocasionó distanciamiento y desconfianza de los países vecinos.

A la vez, se presenció un énfasis en seguridad, una tensión con los vecinos que condujo a mirar otros mercados en 2008, cuando se rompen relaciones con Ecuador. El deterioro con Venezuela y Ecuador se dio desde inicios del presente siglo, no obstante, fue hacia 2007 que las relaciones se muestran más tensas hasta llegar a una ruptura con Ecuador en marzo de 2008, dando lugar a una triangulación de las relaciones de nuestro país con Venezuela y Ecuador (Ardila \& Amado, 2010). Estos dos países eran grandes destinatarios de las exportaciones colombianas, con productos de valor agregado y con una balanza comercial favorable para nuestro país. Es a partir de entonces que Colombia empieza a mirar otras áreas geográficas para el destino de sus exportaciones como el Asia-Pacífico y a fortalecer relaciones diplomáticas con países latinoamericanos como Brasil, Chile y Perú. 
Durante estos años, la política exterior enfatizó en la seguridad y en la diplomacia económica, y fue, a su vez, un instrumento del programa de seguridad democrática orientado a buscar cooperación económica y militar, al mismo tiempo que legitimidad para su proyecto político. Muchos analistas sostuvieron que Colombia carecía de una política exterior y que el país se encontraba aislado del escenario internacional.

Con la llegada de Juan Manuel Santos a la Casa de Nariño, se observa un giro pragmático que enfatiza en América Latina y en la diversificación de sus relaciones externas. Se construyeron nuevas alianzas internacionales, se fortalecieron relaciones con los vecinos y se recobró la institucionalidad, aunque continúe una diplomacia presidencial. Estos cambios van acompañados de un retorno al multilateralismo, una actuación del país en el Consejo de Seguridad de las Naciones Unidas en calidad de miembro no permanente y una actuación en organismos regionales como Unasur. Sin embargo, tan solo coyunturalmente se tiene en cuenta a la sociedad civil.

\section{La participación de los actores no gubernamentales y la existencia de diplomacias paralelas}

Con la globalización y el surgimiento de nuevos temas y actores internacionales, el sistema internacional cambió y el Estado dejó de ser el único actor de la política exterior. Desde finales del siglo Xx, se acaba el monopolio del Estado en las relaciones internacionales (Badie, 2008; Riordan, 2005), y se asiste a un mundo con múltiples centros de poder que crea una proliferación de actores no estatales y una gobernanza por encima de los propios Estados (Rosenau, 1996). Se presencia un agotamiento de la matriz estado-centrista.

Se origina un cuestionamiento acerca del papel de los nuevos actores y se transita hacia dos modelos principales de diplomacia no gubernamental: por un lado, la colaborativa con el Estado que se denomina 'diplomacia ciudadana', y, por otro, la confrontacional y alternativa que cuestiona las acciones del Estado. Estas nuevas diplomacias van a depender de la voluntad y apertura del régimen político, de la identidad y articulación, de los objetivos comunes que se persigan y de una 
interdependencia activa entre sus miembros (Badie, 2008). Sea colaborativa o confrontacional es una diplomacia paralela (Ardila, 2009).

No obstante, los nuevos actores son heterogéneos, se encuentran fragmentados y les falta coordinación y articulación, pero se vinculan a nivel local, nacional, regional y transnacional (Mato, 2004). Al mismo tiempo, varía su representatividad y legitimidad. En este sentido, los empresarios generan mayor confianza en el Estado que las organizaciones no gubernamentales; y los académicos, por su objetividad y cientificidad, brindan una legitimidad técnica. En Colombia, hay ONG muy activas y diversas que tienen una proyección claramente internacional. Las de derechos humanos son de las más activas.

Colombia se asemeja a un sistema político cerrado y penetrado por los valores de las élites dominantes (Rosenau, 1996), en el cual la toma de decisiones es "producto de un proceso informal entre la élite gubernamental y los distintos grupos de interés" (Rosenau, 1996). Es uno de los países latinoamericanos en los que menos participan los actores no gubernamentales en el proceso de toma de decisiones, poco se les consulta y se desconfía de ellos. Cuando se les consulta, se hace de manera coyuntural, intermitente y personalizada (Ardila, 2009). Ello se debe a la estrechez del régimen político colombiano y al conflicto interno, respecto al cual el gobierno teme los vínculos de las guerrillas con otros países y con ONG que a su vez interactúen con actores ilegales.

En un contexto de apertura del Estado, algunos países empiezan a interactuar con los actores no gubernamentales, en el nivel de la consulta y la retroalimentación, sin olvidar que la responsabilidad en la toma de decisiones de la política exterior de un país continúa en el Estado, pero que estos nuevos agentes podrán colaborar y enriquecer tanto la formulación como la ejecución de las acciones externas de un país. En América Latina, dicha interlocución con los actores no gubernamentales se ha presentado en situaciones de modernización del Estado, de democratización o de crisis. Países como Ecuador y México se han abierto en este sentido. 
Aparentemente, desde 2005, el Estado mexicano interactúa de manera orgánica e institucionalizada con la sociedad civil. Se han realizado consultas públicas en temas de seguridad y comercio, por medio de la radio e internet. A su vez, se definieron los parámetros de participación para las organizaciones de la sociedad civil en cuatro niveles: información, consulta, diálogo y participación en delegaciones mexicanas. Así, por ejemplo, en el Plan Puebla-Panamá —actualmente denominado Proyecto Mesoamérica — se contempla la participación de la sociedad civil. También la Secretaría de Relaciones Exteriores realiza talleres de diferente naturaleza y sobre variados temas, como el de infraestructura, biocombustible y medio ambiente.

Teniendo en cuenta las anteriores consideraciones, podemos afirmar que, a diferencia de México, en Colombia permanece la fragmentación de las acciones externas y que nos encontramos lejos de una diplomacia democrática, participativa y coordinada, y que la estrechez del régimen político continúa. La participación de actores no gubernamentales no ha ido acompañada de una apertura democrática gubernamental y se carece de una instancia institucionalizada que consulte y coordine acciones con la sociedad. Las acciones han sido reactivas, coyunturales y personalizadas.

La falta de interacción del Estado con los actores no gubernamentales ha ocasionado diplomacias paralelas o de segunda vía — second track diplomacy - y la superposición de varias políticas exteriores: las del gobierno y las de la sociedad. Incluso, en ocasiones se habla de varias cancillerías y de varias políticas exteriores gubernamentales. Dentro de ellas, también se ubica la paradiplomacia o diplomacia de las regiones, que en el caso colombiano, a diferencia del de México, se encuentra desvinculada del gobierno central.

\subsection{Percepción frente a la democracia y los temas internacionales}

Partiendo de las tipologías señaladas, Colombia y México, aunque con diferente magnitud, hacen parte de un grupo de países que requieren profundizar la democracia y avanzar en un proceso de democrati- 
zación social, es decir, de consolidar una democracia con calidad vinculada con el desarrollo y el bienestar económico de la población.

Los colombianos y los mexicanos apoyan la democracia como la mejor forma de gobierno, aunque la percepción que tiene la ciudadanía se encuentra impregnada por el conflicto interno, los problemas de seguridad (como crimen transnacional e inseguridad ciudadana), las instituciones, la corrupción, el desempleo y la pobreza (Latinobarómetro, 2012).

A su vez, encuestas de opinión pública indican diferencias de satisfacción frente a los gobiernos de Álvaro Uribe y Juan Manuel Santos, mostrándose favorables al mandatario actual. Prefieren una serie de prioridades orientadas hacia las relaciones con América Latina, la ayuda de los Estados Unidos, la protección de los derechos humanos y del medio ambiente. Así mismo, son partidarios de la diversificación de las relaciones internacionales, ven a Brasil como un país líder y prefieren el poder suave al militar (Tickner y Botero, 2011).

No obstante, el tema de la política exterior ha sido poco discutido y la población se encuentra escasamente informada sobre el acontecer externo. Y en esto los medios de comunicación tienen su cuota de responsabilidad, debido a que, cuando más informan sobre política exterior colombiana, es cuando se presenta alguna crisis bien sea con Ecuador, Venezuela o Nicaragua. Durante los últimos años, el análisis internacional ha mejorado, aunque continúa siendo precario.

En cambio, los mexicanos tienen una gran identidad, se interesan por los temas internacionales, se informan, debaten y son pragmáticos. Los del norte son muy diferentes a los del sur. Los primeros son más modernos. Hacia los Estados Unidos tienen sentimientos ambivalentes: desconfían de este país, aunque es su principal socio, y sienten gran afinidad. Quisieran ser puente entre los Estados Unidos y América Latina (Shavion, 2007). Discuten más aspectos internacionales que los colombianos y están mejor informados. 
La vida democrática se enriquece cuando hay canales fluidos de comunicación con los ciudadanos, y mecanismos permanentes e institucionalizados de consulta con esos actores no gubernamentales que definitivamente inciden directa o indirectamente en el proceso de toma de decisiones. La información, formación y articulación de redes sociales han contribuido en este sentido. La carencia de canales institucionales de interlocución con los ciudadanos hace que se den democracias de baja intensidad que llevan a diplomacias paralelas, muchas veces confrontacionales y alternativas, como las de algunas ONG. La democracia requiere de mecanismos e instituciones de interlocución, como los partidos políticos que aglutinen y representen los intereses de la sociedad.

\section{Reflexión final. A manera de conclusión}

México y Colombia son potencias regionales de diferente rango. La primera reúne una serie de capacidades que la ubican mejor que Colombia. Tiene una política exterior activa que prioriza el multilateralismo, con unos indicadores superiores, como el económico y el social. No obstante, presenta problemas internos vinculados con el narcotráfico, la corrupción y situaciones de violencia, así como su relación estrecha con los Estados Unidos, que alteran su ubicación en la jerarquía de poder regional e internacional. En su categorización como países de diferente rango, pesan tanto las variables cuantitativas como las cualitativas. Estas últimas se vinculan con la legitimidad, el liderazgo y el discurso.

Ambos países son procore, dependientes y pragmáticos. Combinan diferentes tipos de inserción, la bilateral con la multilateral, la reactiva con la proactiva y la ideológica con la pragmática.

Durante los gobiernos del PRI, el gobierno azteca manejó un discurso de autonomía que ha venido variando y se ha situado al lado de los Estados Unidos. En la actualidad, busca acercarse a América Latina y, para ello, utiliza grupos regionales, como la Alianza del Pacífico, y la profundización de relaciones con países como Chile y Colombia. Desde 2010, este último y con un carácter también pragmático se 
empeñó en mostrar una imagen diferente. Ambos son partidarios de modelos de integración aperturistas y del regionalismo abierto, y profundizan en la diplomacia económica.

A su vez, presentan una dualidad regional sur-norte y sur-sur, debido a sus complejas y múltiples pertenencias. Apoyan el multilateralismo, mucho más México, pero privilegian prácticas bilaterales, lo cual resulta claro en su carrera por suscribir tratados de libre comercio. Pero, de todas maneras, México lidera el Proyecto Mesoamérica, mientras Colombia, hasta el momento, carece de seguidores y de países a quienes guiar. El 'liderazgo' que ejerce Colombia es transitorio y compartido con otros países.

A manera de reflexión y como punto de partida para futuras investigaciones, este artículo vincula la política exterior con la democracia teniendo en cuenta tres variables: la interdependencia, la seguridad y la relación con los actores no gubernamentales. En cuanto a la primera, se observan similitudes entre Colombia y México en cuanto a su relación cercana con los Estados Unidos. Para ambos, esta potencia ha sido el principal referente para la política exterior, tratando de buscar una diversificación en la que pesan más elementos estructurales que coyunturales.

Igualmente, la pérdida de territorio se presentó en los dos países, situación que dejó una huella en el diseño de su política exterior. El primero va a fluctuar en una contradicción entre la autonomía que han buscado fallidamente los gobiernos priistas y la diversificación también fracasada porque más del $80 \%$ de las exportaciones aztecas se dirigen a su vecino del norte. Algo similar ocurre con Colombia, hace esfuerzos de diversificación hacia el Asia-Pacífico y de acercamiento hacia países latinoamericanos. Al tener múltiples pertenencia y ambos hacia el mar Caribe y el Pacífico, buscan potencializar su ubicación geoestratégica.

En cuanto a la seguridad, esta tiende a vincularse con las fronteras, los derechos humanos, la migración y el medio ambiente. Mientras Colombia tiende a ampliar su concepción hacia una visión multidi- 
mensional, México, debido a sus problemas internos de violencia en general, complementa su concepción basada en el desarrollo con una más tradicional que enfatiza en la defensa y en el combate al narcotráfico, afectando situaciones de vulnerabilidad de la población en materia de derechos humanos. Colombia le ha brindado cooperación al país azteca en temas de seguridad.

En su relación con los actores no gubernamentales, ambos avanzan en la gobernabilidad e institucionalidad democrática, y en la consulta a la sociedad civil. México lo hace de manera institucionalizada y frecuente, y Colombia de forma coyuntural y temática. Son diplomacias democráticas de baja intensidad, debido a que son más reactivas que propositivas; reaccionan ante presiones de la sociedad; y en muchos casos, como el colombiano, son intermitentes y coyunturales?.

Los dos apoyan la democracia. México, un país con un índice de desarrollo democrático medio, mientras que Colombia con un índice de desarrollo democrático bajo, en lo cual influye el conflicto interno, la estrechez del régimen político, la ausencia de debates sobre su política exterior y de interacción entre el Estado y la sociedad.

La democracia se hace cada vez más compleja y no es suficiente examinarla exclusivamente según el régimen político o la periodicidad de sus elecciones, sino que ella depende de su contexto, de variables internas y externas, y, en último término, de su calidad en cuanto a la percepción y satisfacción que tiene la población.

Aunque resulta impreciso definir la democracia por las diversas percepciones y velocidades de su transición, consolidación y profundización

\footnotetext{
9 La diplomacia democrática de baja intensidad fue tomada con base en la 'guerra de baja intensidad', concepto utilizado para Centroamérica por la doctora Lilia Bermúdez, quien lo planteó en la década de los ochenta y los noventa. Se orienta a la habilidad para reaccionar ante cambios rápidos, más que a la proposición. Ver Bermúdez, L. (1987). Guerra de baja intensidad. Reagan contra Centroamérica. Editorial Siglo XXI, tercer capítulo, especialmente págs. 74-75. Si el concepto lo aplicamos a la democracia-diplomacia, estaríamos hablando de: a) una diplomacia reactiva más que propositiva, b) una diplomacia que reacciona a presiones de la sociedad, c) una diplomacia que no es continua, sino intermitente y coyuntural.
} 
en el continente, en este artículo consideramos que la democracia en Colombia y México requiere de una profundización — que se deriva de democracia restringida o semiautoritaria-. Colombia se asemeja a un sistema político cerrado (Rosenau, 1996) y a una democracia de baja intensidad. Y México, impregnado de rasgos autoritarios, donde durante muchos años predominó un partido hegemónico, el PRI, que obstaculizó espacios de interlocución, el cual ha regresado al poder. En este sentido, podríamos referirnos a la necesidad de una "democratización social" (Munk, 2002) o multinivel, que incluya lo político, lo económico y lo social, pero también lo internacional.

La democracia en América Latina sufre síntomas de resquebrajamiento cuando se creía que había una consolidación, y es lo que ha sucedido con liderazgos autoritarios o democracias delegativas en Venezuela y Honduras. En general, se observa una carencia de institucionalidad democrática marcada por la falta de confianza en las instituciones y de una mayor y continua interacción con los actores no gubernamentales.

Se necesita desarrollar una agenda para la gobernabilidad democrática, construir confianza en las instituciones, una mayor participación de la sociedad civil y, en general, una modernización y actualización gubernamental que brinde una participación activa e institucionalizada de actores diferentes al Estado. Para ello, se requiere de la cooperación multilateral, el fortalecimiento de los instrumentos para la promoción de la democracia, la equidad, la transparencia, la inclusión, la protección de los derechos humanos y la lucha contra la pobreza.

Colombia siempre fue vista como una democracia formal y estable, con elecciones periódicas, aunque atravesada por múltiples crisis, como la de representatividad, la de gobernabilidad y la del Estado, y también afectada por el conflicto interno. La crisis de representación causó la pérdida de las fronteras ideológicas entre los partidos, reemplazándolas por intereses clientelistas que determinaron el descrédito y la desconfianza del electorado. Esto llevó a que los partidos dejaran de actuar y de ser vistos como intermediadores entre las dos esferas de la política, la sociedad civil y el Estado. Esta crisis se vinculó con la 
falta de confianza en sus instituciones y en el manejo de la política exterior. Desde antes de los noventa, empieza a hablarse de una crisis de gobernabilidad, de un Estado fallido y de un país problema que exporta inestabilidad hacia sus vecinos (Kornblith, 2004).

Los desafíos que hoy afronta la democracia se orientan a la profundización, relevancia y calidad de los regímenes democráticos. La calidad de la democracia está relacionada con el fenómeno de expansión de la ciudadanía, es decir, con los problemas de participación, representación y satisfacción ciudadana en los procesos de toma de decisiones. Si bien es cierto que sin elecciones no hay democracia, sin sociedad que participe organizadamente tampoco hay democracia plena.

Teniendo en cuenta las anteriores consideraciones y para concluir, podemos afirmar que la vinculación de la política exterior con la democracia colombiana y mexicana son de baja intensidad y presentan una 'legitimidad media', debido al limitado papel de los partidos políticos, la desconfianza en las instituciones, la falta de transparencia, la corrupción y el clientelismo. No obstante, México tiene un servicio exterior más profesionalizado y en él se debaten más los temas de política exterior.

Ambos países comparten intereses por afianzar una diplomacia económica, pero requieren de una diplomacia más participativa, incluyente, institucionalizada y activa. Para ello, deben construir políticas de Estado coordinadas con diversas entidades gubernamentales y con la sociedad civil. Colombia debe abandonar la estrechez del régimen político y abrirse a diferentes actores que vayan más allá de los valores de las élites dominantes. Y, sobre todo, que la política exterior refleje el interés de la población.

\section{Referencias}

Ardila, M. (enero-junio, 2009). Actores no gubernamentales y política exterior. Colombia Internacional, (69).

Ardila, M. et al. (2008). La toma de decisiones de la politica exterior colombiana. Bogotá: Universidad Externado de Colombia. 
Badie, B. (2004). Da soberania à competência do Estado. Smouts, MarieClaude. As novas relações.

Badie, B. (2008). Le diplómate et l'intrus. Fayard.

Bernal-Meza, R. (enero-junio, 2009). México: del 'autonomista' potencia media al socio subordinado de Estados Unidos. Estudios Internacionales, 1(1).

Cavarozzi, M., \& Casullo, E. (2001). Los partidos políticos en América Latina: ¿consolidación o crisis? En M. Cavarozzi \& J. M. Abal Medina (Eds.), El asedio a la política. Rosario: Homo Sapiens.

Corporación latinobarómetro. (2012-2013). Informe Latinobarómetro.

Recuperado de www.latinobarometro.org

Desdradi, S. (2009). Regional powers and their strategies: empire, hegemony, and leadership. Review of International Studies, (36), 903-930.

El Tiempo. (2013).

Ellner, S. (2012). The distinguishing features of Latin America's new left in power the Chávez, Morales, and Correa governments. Latin American Perspectives, 39(1), 96-114.

Flemes, D., \& Wenher, L. (October, 2012). Drivers of strategic contestation in South America. GIGA, (207).

Gallón, G. (2002). Diplomacia y derechos humanos en Colombia. En M. Ardila et al., Prioridades y desafios de la politica exterior colombiana. Bogotá: Fescol.

González, G., Schiavon, J., \& Crow, D. (2011). Las Américas y el mundo 20102011. Opinión pública y politica exterior en Brasil, Colombia, Ecuador, México y Perú. México: Centro de Investigaciones y Docencia Económica (CIDE). KAS. (2012). Índice de desarrollo democrático de América Latina. IDD-Lat 2012. Fundación Konrad Adenauer.

Kornblith, M. (2004). Percepciones venezolanas sobre la crisis de Colombia. Colombia Internacional, (60).

Mato, D. (2004) Redes transnacionales de actores globales y locales en la producción de representaciones de ideas de sociedad civil. En D. Mato (Coord.), Politicas de ciudadanía y sociedad civil en tiempos de globalización. Caracas: Faces, Universidad Central de Venezuela.

Munck, G. (enero-marzo, 2002). Una revisión de los estudios sobre la democracia: temáticas, conclusiones, desafíos. Revista de Desarrollo Económico, 41(164). 
Notle, D. (2010). How to compare regional powers: analytical concepts and research topics. Review of International Studies, (36), 881-901.

Pellicer, O. (2006). México-a reluctant middle power? New Powers in Global Change, Dialogue on Globalization.

Pérez Llana, C. (2007). Modelos políticos internos y política exterior en América Latina. Foreign Affairs en Español, (4), 7.

Plan Nacional de Desarrollo 2013-2018. (2012). México.

Ramírez Chaparro, C. (2012). Anatomía de un actor: el Ministerio de Defensa Nacional y la política exterior colombiana. En S. Jost (Ed.), Colombia: ¿una potencia en desarrollo? Bogotá: KAS-Universidad Javeriana.

Rocha Valencia, A., \& Morales, D. E. (2011). Potencias medias. Potencias regionales en el sistema internacional de Guerra Fría y Posguerra Fría. Propuesta de dos modelos teóricos. Universidad de Guadalajara.

Rosenau, J. (1996). Pre-theories and theories of foreign policy. En J. A. Vásquez (Ed.), Classics of international relations. Upper Saddle (NJ): Prentice Hall.

Russell, R., \& Tokatlian, J. (diciembre, 2013). América Latina y su gran estrategia: entre la aquiescencia y la autonomía. Cidob D'Afers Internationals, (104).

Tickner, A. B., Pardo, O., \& Beltrán, D. (2006). ¿Qué diplomacia necesita Colombia? Bogotá: Universidad de los Andes.

United Nations. (22 October-1 November, 2013). Human Rights Council. Working Group on the Periodic Review, seventeenth session, Geneva.

Velázquez Flores, R. (2008). La relación entre el ejecutivo y el Congreso en materia de política exterior durante el sexenio de Vicente Fox: ¿cooperación o conflicto? Política y Gobierno, 15(1).

Villamar, Z. (2013). La política exterior mexicana tras el regreso del PRI. Una visión para los próximos seis años. Nueva Sociedad, (247), 16-25.

\section{Páginas web}

www.economia.gob.mx www.elespectador.com www.eltiempo.com www.jornada.unam.mx www.nexos.com.mx www.proceso.com.mx 
252 / MARTHA ARDiLA

www.promexico.gob.mx

www.semana.com

www.unomasuno.com.mx 